NASA Technical Memorandum 83628

\title{
Characterization and Measurement of Polymer Wear
}

Donald H. Buckley and Paul R. Aron

Lewis Research Center

Cleveland, Ohio

Prepared for the International Symposium on Polymer Wear and Its Control sponsored by the American Chemical Society St. Louis, Missouri, April 9-11, 1984 


\title{
CHARACTERIZATION AND MEASUREMENT OF POLYMER WEAR
}

\author{
by Donald H. Buckley and Paul R. Aron \\ National Aeronautics and Space Administration \\ Lewis Research Center \\ Cleveland, Ohio $\mathbf{4 4 1 3 5}$
}

\begin{abstract}
A host of analytical tools are available to assist the tribologist in understanding and characterizing the polymer wear process. They can be used in the study of polymer wear and the development of polymer transfer films to nonpolymer counterfaces. Some of the devices discussed include visual observation of polymer wear with SEM, quantifying it with surface profilometry and ellipsometry, studying chemistry with AES, XPS and SIMS, establishing interfacial polymer orientation and accordingly bonding with QUARIIR, polymer state with Raman spectroscopy and stresses that develop in polymer films using a $X$-ray double crystal camera technique.
\end{abstract}

\section{INTRODUCTION}

When any two surfaces are brought into solid state contact and subsequently separated the nature of one or both surface frequently has changed as a result of the contact. It is even more likely to occur when mechanical forces are imposed on the contact. Polymeric materials are not different than other solids in this respect. The surface and near surface changes that have occurred in polymers may however be more difficult to characterize, in part because of the difficulty in identifying these materials with analytical tools.

Wear in a strict sense occurs whenever material is lost from a solid. The mechanism of loss can be abrasion, adhesion, erosion, cavitation, corrosion or fatigue. This loss can occur at the atomic level. At this level anaiytical tools such as the field ion microscope and the atom probe can be used to study wear loss of polymers. These tools have been used in the authors laboratory for many years to study polymer adhesion and transfer to metal surfaces (refs. 1 and 2). They are capable of providing insight into the presence or absences of transfer (wear), the adhesive strength of polymer to metal, amount of transfer, bond scission, mechanical effects such as loading of surfaces together, chemical effects on bonding and surface energetics. The field ion microscope coupled with the atom probe is the ultimate tool for the study of polymer wear because it allows the analysis both structural and chemical of the wear process at the atomic level. While the field ion microscope with the atom probe may be the ultimate in polymer wear analysis in many instances such depth may not be required as the wear process may be a relatively gross event. In such cases much more conventional tools may be used to characterize polymer wear. Two such tools are the surface profilometer and the scanning electron microscope (SEM). These devices provide a macroscopic picture of the wear of polymers.

There are many other analytical tools that can assist the tribologist in the characterization of the polymer wear. Many of these tools including those 
discussed herein are described fully in Ref. 3 where their capabilities, sensitivities and limitations are given in detail. They can identify quantity of polymer transferred to a counterface surface (ellipsometer), amorphous verses crystalline state (Raman spectroscopy). stresses in transfer films and worn polymer surfaces (double crystal $X$-ray techniques), orientation of transferred molecules of polymer on the counterface (reflection-absorption infrared spectroscopy; RAIR), bonding mode (inelastic electron tunneling spectroscopy, IETS), elements present in polmer wear debris (Auger electron-spectroscopy, AES), mapping of polymer wear surface distribution (scanning Auger microscopy. SAM), distinguish between various homologs (low damage secondary ion mass spectrometry. SIMS) and interfacial polymer to counterface chemical analysis (X-ray photoelectron spectroscopy, XPS).

The objective of this paper is to review the wear of polymers using the above tools in order to characterize the wear process. Wear analys is will include microscopy observation, profiling, thickness measurements and chemistry both structural and analytical.

\section{VISUAL OBSERVATION OF THE WEAR SURFACE}

The visual observation of the polymer wear surface is the simplest method for characterizing the wear process. Frequently a considerable amount of very useful information can be gained from the use of the light optical and scanning electron microscope studies of the polymer surface that has undergone wear.

An example of how visual observation can assist in wear studies has been demonstrated in the erosion behavior of thermoplastics (ref. 3). In the erosion of polymers the shape of the impinging particle on the polymer surface determines the mechanism by which wear occurs. If the particle is relatively smooth and spherical wear to the polymer surface occurs by the formation of deformation flakes, fracture and sub-surface fatigue. Where the particle have sharp edges the wear process is dominated by cutting analogous to an abrasive grit.

Figure 1 contains micrographs of polymethylmethacrylate (PMMA), polycarbonate (PC) and polytetrafluoroethylene (PTFE) surfaces which have undergone erosive wear by the impingement of glass beads. With all three polymers loss from the surface occurs by flake formation as indicated in each of the micrographs.

\section{PROFILING POLYMER WEAR}

In addition to seeing the wear surface it is often desirable to quantify the loss of polymer due to wear. One of the most straight forward techniques for accomplishing this is to profile the wear area. This can be done with mechanical devices such as a stylus tracking of the profile or for extremely deformation prone surfaces with the use of optical or laser beam profiling.

An example of the use of the profilometer in following the erosive wear of polytetrafluoroethylene (PTFE) is presented in Fig. 2. The profiles of the wear spot, which are circular in nature at the surface, are presented for various periods of exposure time to the erosive particles. With increasing 
time the depth of the pit continues to increase. It is important to note that magnification in the horizontal and vertical directions is not the same. Thus, in using the profiles and integrating the wear area to arrive at total loss, care must be taken to correct for the differences.

The profilometer can also be used to track polymer wear where one material in contact is a polymer and the other is, for example, a metal. If wear occurs by transfer of polymer to the metal, the surface of the metal can be profiled to identify the amount of polymer transferred.

\section{THIN FILM IDENTIFICATION}

Where polymers transfer to counterface surfaces in extremely thin film forms, of the order of monolayers the surface profilometer becomes ineffective and other tools must be used. A device which can measure the thickness of such films is the ellipsometer. It can detect film thicknesses of polymers on the order of angstroms.

In Fig. 3 the film thickness of a polymer is presented as a function of deposition time (ref. 4). It can be seen from the data of Fig. 3 that polymer films of thicknesses of the order of 30 to 40 angstroms can be readily detected by ellipsometric techniques. This device, then, permits the transfer of extremely thin polymer films and allows for the identification of the onset of adhesion and transfer. providing the opportunity to identify when bonding occurs and some indication of bond strength. If the polymer is seen to transfer to a counterface surface, then it is reasonable to assume that the interfacial adhesive bond strength is greater than the cohesive strength of the polymer itself. This observation will only hold where the counterface surface is atomically smooth.

\section{THE CHEMISTRY OF POLYMER WEAR}

\section{Devices}

The tools described thus far in this paper present a physical view of polymer wear. What about the chemistry of the polymer wear process? In studying chemistry it is desirable to have the analytical tool incorporated directly into the wear experiment. An example of such a device is presented in the schematic of Fig. 4 from the authors laboratory.

Figure 4 presents what is commoniy referred to as the pin on disk friction and wear device. A hemispherical rider mounted in a beam is loaded against a rotating disk. The disk is rotated unidirectionally. The beam containing the rider is mounted in a gimbal which is connected to a strain gage assembly for measuring friction force.

Wear to the rider and disk can be measured periodically or upon completion of an experiment. One or both specimens can be polymers or polymer compositions.

The system depicted in Fig. 4 contains the components for XPS analysis of the disk and ion depth profiling for the removal of surface films and polymer 
layers. $X$-rays are the excitation for the emission of electrons from the surface whose binding energies are measured with the analyzer. A beam of argon ions are directed at the surface in the location of analysis for depth profiling.

The beam of $X$-rays strike the surface of the disk in Fig. 4 at a location of $180^{\circ}$ from where the rider contacts the disk. Thus, changes in surface chemistry in the wear track can be continuously monitored during the course of an experiment. A similar type of device is used for Auger analysis (AES) only the excitation source is a beam of electrons rather than $X$-rays as used for XPS. With AES an elemental analysis is obtained while with XPS compounds and changes in polymer chemistry can be followed.

\section{Surfaces and Interfaces}

Sliding friction and wear experiments were conducted with polytetrafluoroethylene (PTFE) sliding of nickel. An important question to be asked is does the polymer chemistry change when it undergoes wear? There is a considerable amount of energy dissipated at the sliding interface and this energy could conceivably degrade or alter the polymer from that observed for the bulk unworn polymer.

Figure 5 presents the fluorine KLL Auger spectra for both bulk PTFE and the wear transfer film (ref. 5). Feature 1 involves the $2 \mathrm{~s}$ and $1 \mathrm{~s}$ electrons, while feature 2 involves the $2 p$ and 15 electrons and would be expected to change size with a change in chemical bond. Thus, a change in the ratio of feature 2 to feature 1 is indicative of a change in the chemical state of the film. Although the features are not sharp and feature 1 is particularly difficult to measure, there is no difference in the spectra beyond the limit of uncertainties. The transfer polymer wear film is therefore the same as the bulk PTFE.

The data of Fig. 5 tell us that the surface of the transfer film has the same chemistry as the bulk polymer. Auger analysis is surface sensitive and probes only to a depth of four to five atomic layers. What about the chemistry at the interface between polymer and metal? Is there any chemical interaction resulting from the sliding process and contributing to polymer wear? XPS with ion depth profile analys is can assist in answering these questions. First, XPJ probes more deeply than AES and secondly ion depth profiling can assist in getting to the interface through removal of thick polymer wear transfer films and thereby arrive at the interface.

The XPS spectrum of Fig. 6 for the $F(1 \mathrm{~s})$ peak indicates that at the nickel to polymer interface some nickel fluoride $\left(\mathrm{NiF}_{2}\right)$ forms. The amounts is extremely small but is nonetheless present. Both peak heights and film thickness indicate that only an occasional flourine has reacted with the nickel chemically. Since fluorine is monovalent, it is unlikely that it can function in the formation of a strong bond between the metal and the PTFE. The single fluorine bond must interact either with the metal when it forms nickel fluoride or with carbon of the polymer. 
The presence of $\mathrm{NiF}_{2}$ at the polymer metal interface may be indirect evidence for the formation of a metal to carbon bonds. When the fluorine reacts with the nickel a carbon is available for bonding also to the metal.

Just as the ellipsometer can be used to measure polymer film thickness so can XPS. For example, with PTFE by the use of the ratio of intensities of the $F(15)$ and the $C(15)$ peaks and the attenuation of the nickel peak intensities it is possible to measure polymer film thickness and accordingly polymer wear (ref. 5).

Figure 7 indicates the amount of polymer transfer on wear that occurs as a function of a mechanical parameter sliding speed. An examination of Fig. 7 indicates that the higher the sliding speed for a polymer in contact with a metal the greater the film thickness and accordingly the amount of polymer wear.

While Auger electron spectroscopy and $x$-ray photoelectron spectroscopy can give elemental and organic structual information, respectively, they have limitations in the amount of material they can detect. For example, where polymers are in sliding, rolling or rubbing contact with metal or alloys wear to the metal as well as wear to the polymer can occur. Metals have been observed to transfer to polymer surfaces (ref. 6). This transfer can be extremely discrete and difficult to detect in the polymer surface as well as polymer wear debris.

Static or low-damage secondary ion mass spectrometry (SIMS) can be used to characterize polymers and also detect very small amounts of metals transferred to polymers or in polymer wear debris. While SIMS uses an ion beam to sputter remove surface species and is therefore inherently destructive, damage can be minimized by using low ion beam fluxes $\left(3 \times 10^{-9} \mathrm{~A} / \mathrm{cm}^{2}\right)$. This allows for monolayer analysis.

SIMS can be effectively utilized to distinguish, for example, among a series of poly(alkyl) methacrylate films deposited on a metal substrate.

Low-damage SIMS has distinguished thin transfer films of the homologous series of poly(methyl, ethyl, isobutyl, n-butyl and louryl) methacrylates. Figure 8 is a SIMS spectrum from a polylaurylmethacrylate films on a silver substrate (ref. 7).

The mass to change ratios $(\mathrm{m} / \mathrm{Z})$ are detected in $\mathrm{Fig} .8$ for the methy 1 $\left(m / 2\right.$ 15) ethyl $(m / 2 ~ 29)$, propyl $(m / 2 ~ 43)$ ions as well as that for $\left[\mathrm{C}_{4} \mathrm{H}_{7}\right]^{+}$ion $\left(\mathrm{m} / 2\right.$ 55) associated with the breakup of the lauryl group. The $\left[\mathrm{C}_{4} \mathrm{H}_{7}\right]^{+}$has the greatest intensity. With the poly(methyl and ethyl) methacrylates, the methyl ion $(\mathrm{m} / 2,15)$ and the ethyl ion $(\mathrm{m} / 2$ 29) are respectively the most intense ion species present. In the case of the butylisomers the ethyl ion $(\mathrm{m} / 2 \mathrm{29})$ is dominant over the propyl ion $(m / 243)$ for the iso-butyl isomer while with the n-butyl isomer the reverse is observed. With the lauryl isomer the $(\mathrm{m} / 2 \mathrm{55})$ is the most intense of the four ions and the other ion intensities decrease with decreasing $\mathrm{m} / \mathrm{z}$. Silver is detected in the polymer from the silver substrate.

SIMS has proved to be a very useful tool in polymer film studied and accordingly wear analysis. Various polymers have been fingerprinted with SIMS including in addition to those already discussed, low density, polyethylene, 
polypropylene, polystyrene, nulon-6 and poly(ethyleneterephthalate) (refs. 8 and 9).

\section{Polymer to Counterface Bonding}

of extreme interest to the tribologist is the nature and structure of interfacial adhesion of polymers to substrate surfaces because it contributes heavily to the adhesive wear of polymers. A very useful tool for the study of this subject is quantitative absorption - reflection thickness infrared spectroscopy (QUARTIR). This device is uniquely suited for the study of preferential orientation of large molecules at interfaces. Thus, insight into the structural interfacial bonding of molecules can be had, adhesion and accordingly adhesive wear better understood.

Studies have been conducted with a surfactant, 4,5 dimethoxy-2-nitrobenyl hexadecane sulfonate (PMS) cast in a copolymer-substrate. The structure of the surfactant is indicated in Fig. 9(a). Films of thicknesses from 100 to $1000 \ddot{A}$ on the aluminum substrate were examined.

The use of QUARTIR permitted (1) the analysis from bulk film to near monolayer. (2) quantitatively established individual bond absorbances in the film, (3) allowed for the commutation of frictional changes in normalized absorbance between bulk and interface values, (4) determined the transition moment direction of the modes producing each bond in terms of internal molecular coordinates, and (5) from (3) and (4) made possible the angles of the various transition moments and accordingly molecular coordinates of bonding to the solid surface.

Figure 9 (b) presents the mechanism of bonding of the surfactant PMS to the oxidized aluminum surface. Certainly such information is extremely useful in predicting adhesive bond strengths at interfaces.

\section{Polymer Structure}

In addition to visualization, profiling, thickness measurements and chemistry of polymer wear it is frequently desirable to know whether the polymer is in the amorphous or crystalline state because other properties relate to state. Raman spectroscopy is very useful in studying very low frequency modes associated with vibrations of polymer chain backbones and the lattice modes of polymer crystals. It complements infrared spectroscopy.

The ability of Raman spectroscopy to distinguish between mylar in the crystalline and amorphous state is presented in Fig. 10 taken from Ref. 10. The figure reveals the distinct differences in peak shape with crystallization of the polymer.

Molecular relaxations, and molecular orientation of polymers can be related to tribological performance. Such studies have been conducted with po?yimides (ref. il). 


\section{Stresses in Polymers}

During the sliding, rolling or rubbing process for polymers stresses are generated in the polymer. Where polymers are in contact with metals or alloys transfer films of the polymer generally develop on the counterface. These polymer wear films are generally highly stressed. Until recently there has been no good effective technique for the simple measurement of these stresses. A $X$-ray scheme has been demonstrated as being capable of providing such measurements. It has been used for the measurement of stresses generated in Dolyimide films (ref. 12).

Figure 11 presents a schematic of a double crystal camera arrangement with a) unstrained crystals, and b) a strained crystal. The polymer films have been deposited on single crystal silicon substrates. In Fig. 11(a) an unstrained crystal is in position two, with each crystal aligned to obtain Bragg diffraction in transmission from a set of planes. Translation of the two crystals produces no change in the double-diffracted $X$-ray intensity because the Bragg angle remains constant across the crystal. The crystal in position two of Fig. 11 (b) has a curvature due the stresses generated in the polymer. Translation of the two crystals of Fig. 11 (b) results in a sharp decrease in the double-diffracted $x$-ray intensity due to lattice curvature . Details of the technique can be found in Ref. 12 .

With the $X$-ray technique described stresses in polymer wear films can be measured. One could incorporate a pin on disk friction device within the opening of the $X$-ray camera and conduct "in situ" measurements. The stresses developed in the film with repeated passes, increasing load, varied sliding speeds and polymer compositions can be measured. This could lead to a better understanding of the role of stresses in polymers on their wear behavior.

The effect of temperature on polymer stresses can also be measured. Again, this could be done "in situ". Figure 12 presents a plot of stress as a function of temperature. The data for a polyimide in Fig. 12 indicates that interfacial stress decreases with an increase in temperature. This could be effectively utilized to determine the effect of frictional heating on polymer stress as well as wear.

\section{CONCLUDING REMARKS}

A host of analytical tools are available to the tribologist for the study of the wear of polymers and polymer films. Much can be learned about the wear behavior of polymer with visual observation of the wear surfaces with the scanning electron microscope while surface profilometer can assist in quantifying polymer wear.

The thickness of polymer transfer films to counterface surfaces can be measured with sensitivities into the angstrom range with the ellipsometer. The device can be arranged for in situ thin film measurements.

The chemistry of polymer surfaces and their wear can be measured "in situ" with Auger electron spectroscopy, X-ray photoelectron spectroscopy and secondary ion mass spectrometry. These tools provide elemental, compound analysis and distinguish among a series of homologs respectively. 
Orientation at the interface between polymers and metals where the polymer transfer to the metal can be determined with quantitative absorption-reflection thickness infrared spectroscopy. With an understanding of polymer interfacial orientation, bonding mechanisms can be identified and accordingly adhesion of polymers to metals better understood.

Raman spectroscopy can be used to identify the polymer state and double camera $X$-ray techniques to determine the amount of stresses developed in films of transferred polymers.

\section{REFERENCES}

1. Buckley, D.H. and Brainard, W.A.: "The Atomic Nature of Polymer-Metal Interactions in Adhesion. Friction and Wear." Advance in Polymer Friction and Wear, edited by L.H. Lee, Polymer Science and Technology, Volume 5A. Plenum Press, New York (1974).

2. Buckley, D.H.: "Surface Effects in Adhesion, Friction, Wear and Lubrication," Elsevier, Scientific Publishing Company, Amsterdam, (1981).

3. Characterization of Solid Surfaces, Edited by Kane, P.F. and Larrabee, G.B. Plenum Press, New York 2nd Printing (1976).

4. Rao, P.V. and Buckley, D.H.: "Spherical Microglass Particle Impingement Studies of Thermoplastic Materials at Normal Incidence," NASA TM-83410, (1983).

5. Baba, M. and Gottesfeld, S.: "Ellipsometric Study of the Polymeric Surface Films Formed on Platinum Electrodes by the ELectroxidation of Phenolic Compounds", Surface Science, 96, pp. 461-475, (1980).

6. Wheeler, D.R.: "Polytetrafluoroethylene Transfer Film Studied With X-Ray Photoelectron Spectroscopy," NASA TP 1728, November (1980).

7. Brainard, W.A. and Buckley, D.H.: "Adhesion and Friction of PTFE in Contact With Metals as Studied by Auger Spectroscopy, Field Ion and Scanning.Electron Microscopy," WEAR, 26, PD. 75-93, (1973).

8. Campana, J.E., DeCorpo, J.J. and Colton, R.J.: "Characterization of Polymeric Thin Films by Low-Damage Secondary Ion Mass Spectrometry," Applied Surface Science, 8, pp. 337-=342, (1981).

9. Briggs, D. and Wooton, A.B.: "Analys is of Polymer Surfaces by SIMS: 1 An Investigation of Practical Problems," Sur. and Inter. Ana., 4, 3, pp. 109-115, (1982).

10. Briggs, D.: "Analysis of Polymer Surfaces by SIMS: 2 - Fingerprint Spectra from Simple Polymer Films," Surf. and Inter. Ana 1., 4, 4, pp. 151-155, (1982).

11. Andrews, R.D., and Hart, T.R.: "Use of Laser Raman Technique in the Study of Polymers," Characterization of Metal and Polymer Surfaces, Vol. 2, Polymer Surfaces editor L-H. Lee, Academic Press, pp. 207-241, (1977). 
12. Fusaro, R.L.: Molecular Relaxations, Molecular Orientation and the Friction Characteristics of Polyimide Films." ASLE Trans., 20, 1, pp. 1-14, (1975).

13. Goldsmith, C., Geldermans, P., Bedetti, F. and Walker, G.A.:

"Measurement of Stresses Generated in Cured Polyimide Films," Journal

Vacuum Science \& Technology A1 (2), Pp. 407-409, (1983). 

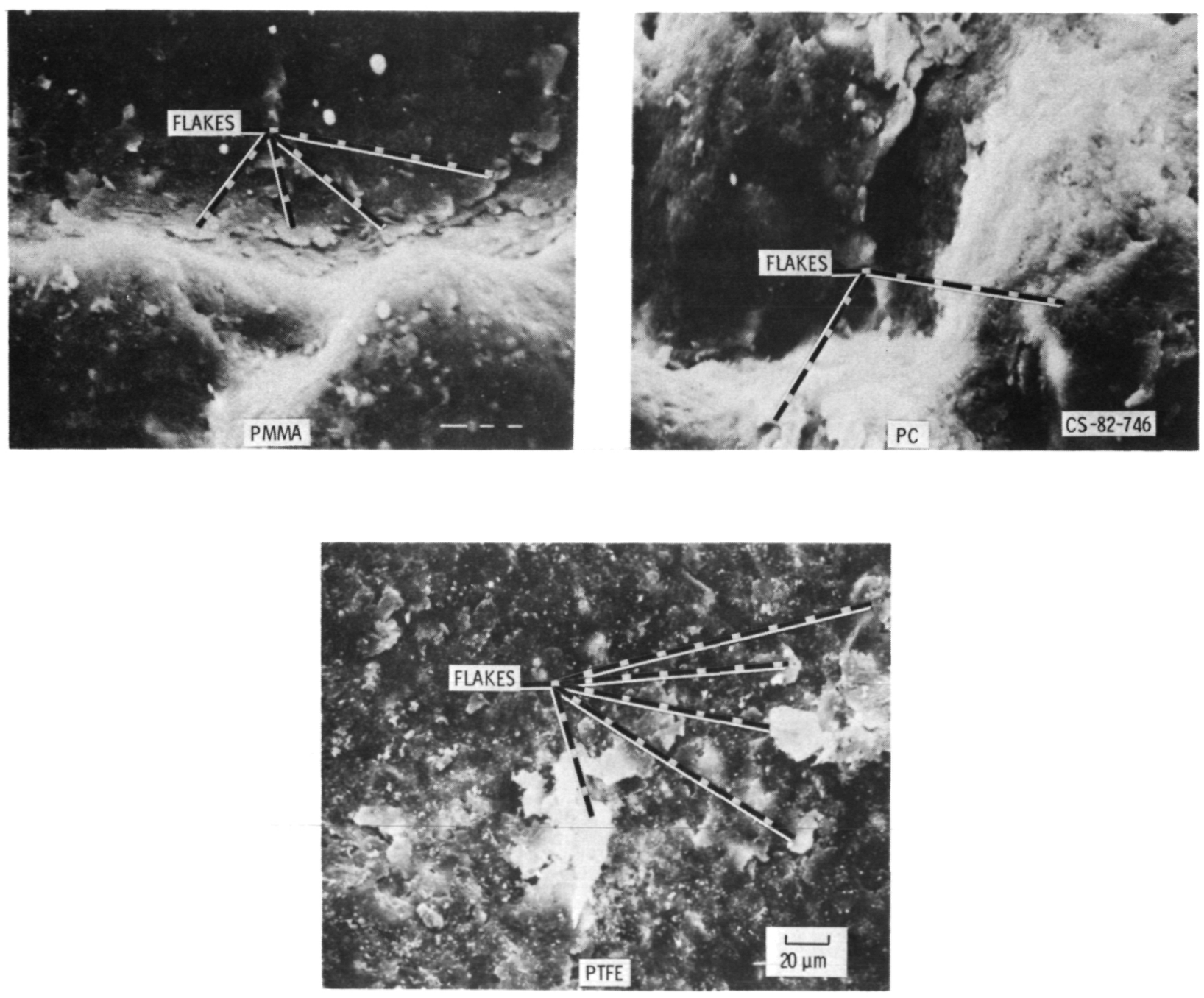

Figure 1. - SEM micrographs $\left(40^{\circ}\right.$ tilt) of eroded thermoplastic material surfaces. Exposure time, $10 \mathrm{~min}$; gas pressure, $0.27 \mathrm{MPa}$. Particle velocity, $72 \mathrm{~m} / \mathrm{s}$. 


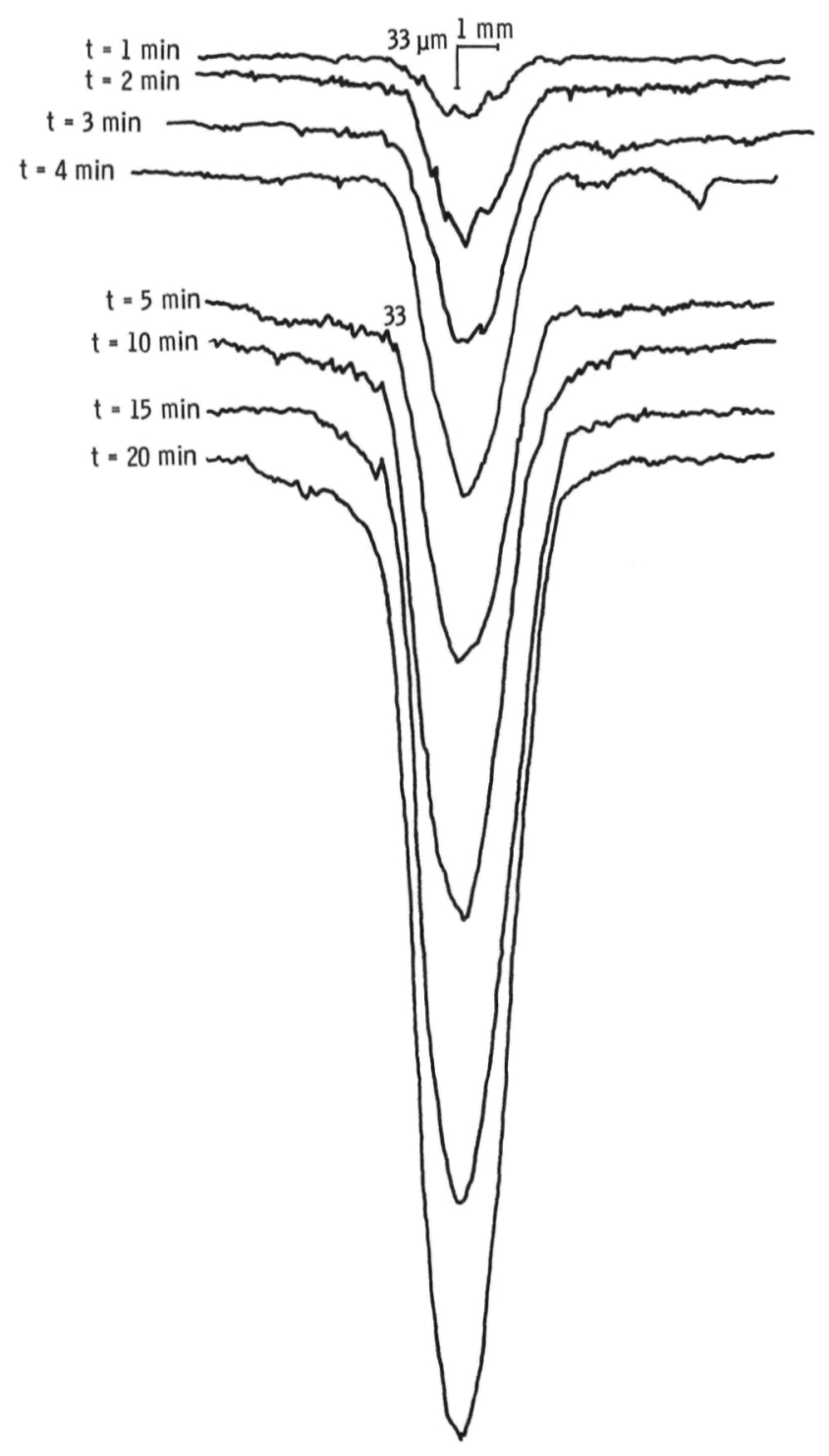

Fig. 2. - Surface traces on PTFE as a function of time.

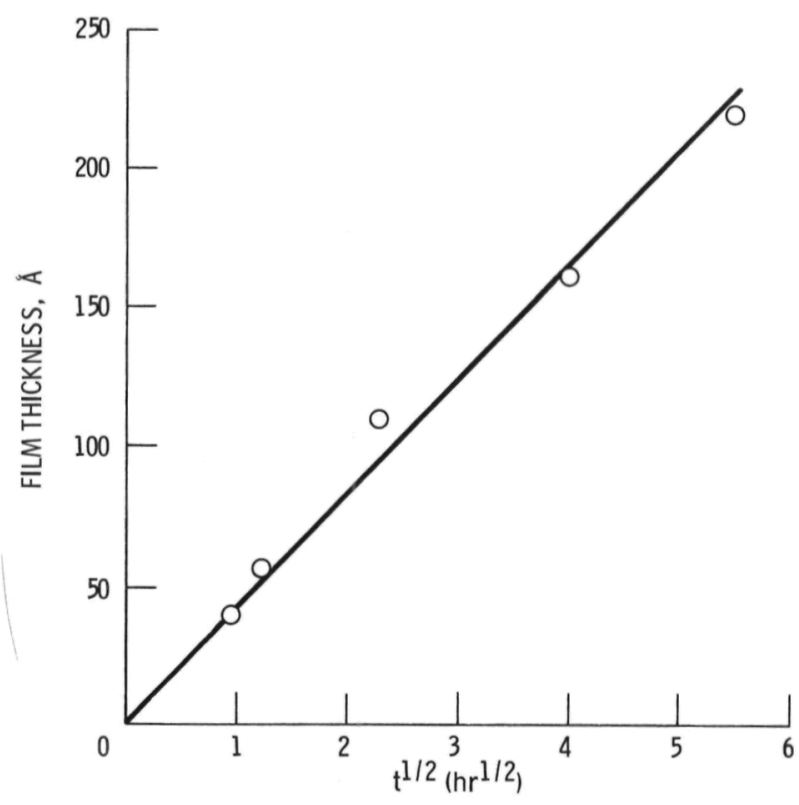

Fig. 3. - The thickness of a polymer film, as measured with the ellipsometer with deposition time (ref. 4). 


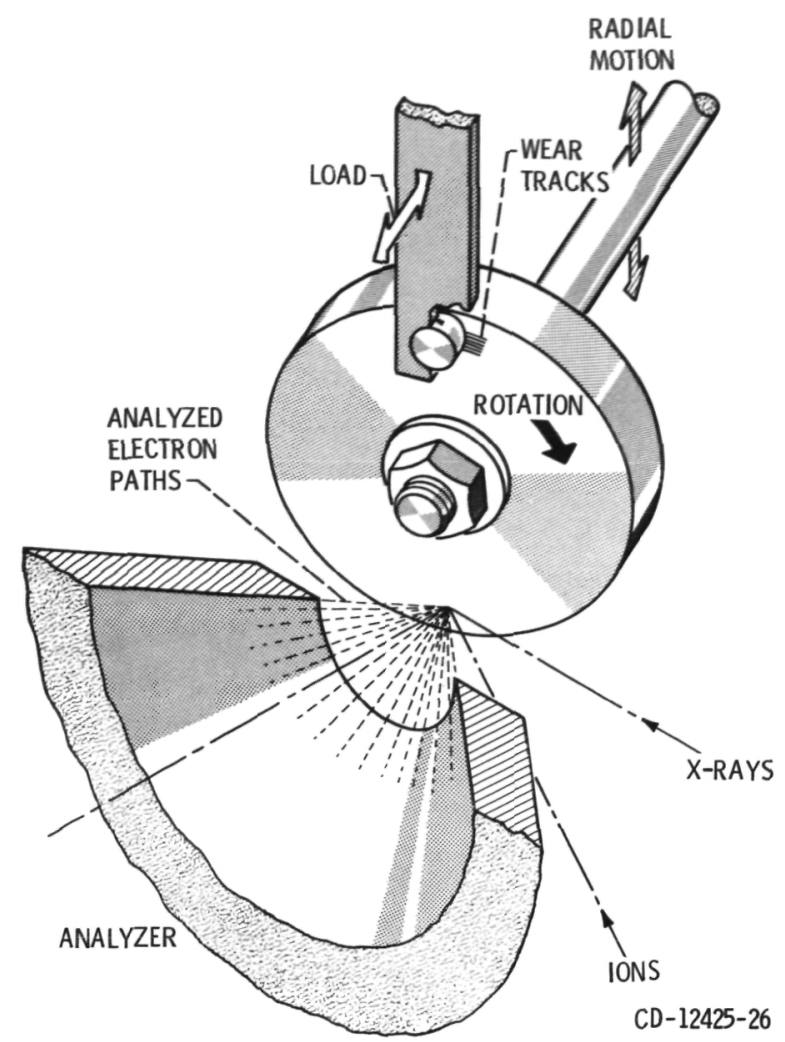

Fig. 4. - Schematic diagram of apparatus for XPS analysis of polymer transfer.

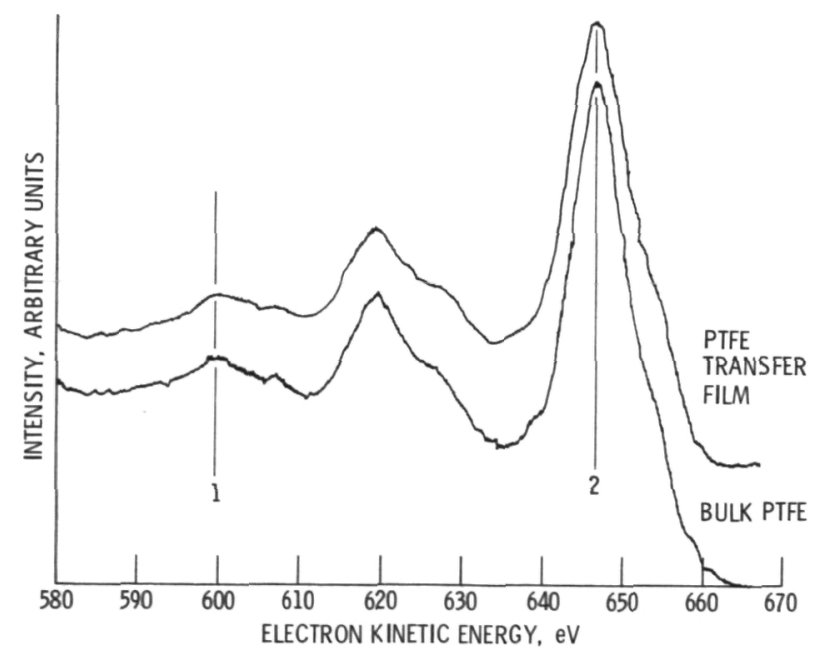

Fig. 5. - Fluorine auger electron spectra from PTFE transfer film ion clean nickel in vacuum and from bulk PTFE. Load, 2 newtons; sliding speed, 0. 94 millimeter per second. (To account for charging, the upper peak is shifted horizontally so that the spectra coincide.) 


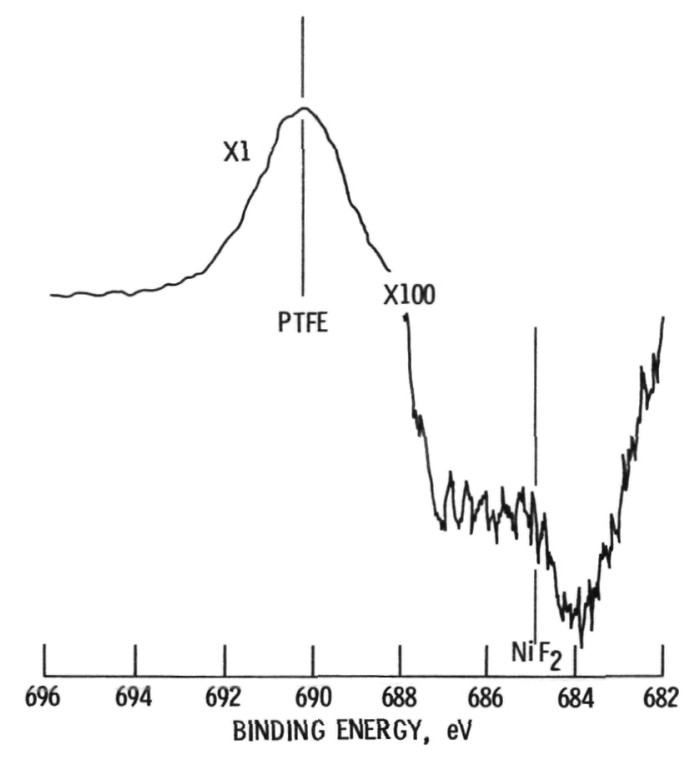

Fig. 6. - F(ls) XPS peak from PTFE transfer film on clean nickel in vacuum. Load, 2 newtons; sliding speed,

0.94 millimeter per second.

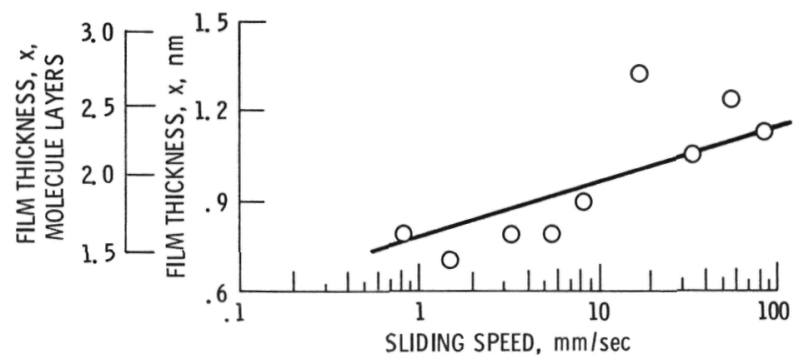

Fig. 7. - Average thickness of PTFE transfer film on nickel at various sliding speeds in vacuum. Load, 2 newtons; temperature, $24^{0}$ to $27^{\circ} \mathrm{C}$.

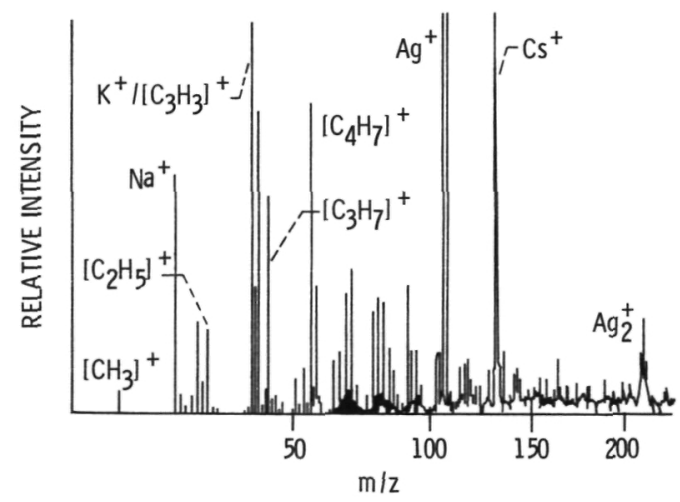

Fig. 8. - Static SIMS spectrum of polylaurylmethacrylate. 


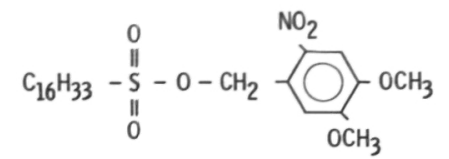

(a) Surfactant (PMS), 4.5 dimethoxy-2nitrobenzylhexadecanesulfonate.

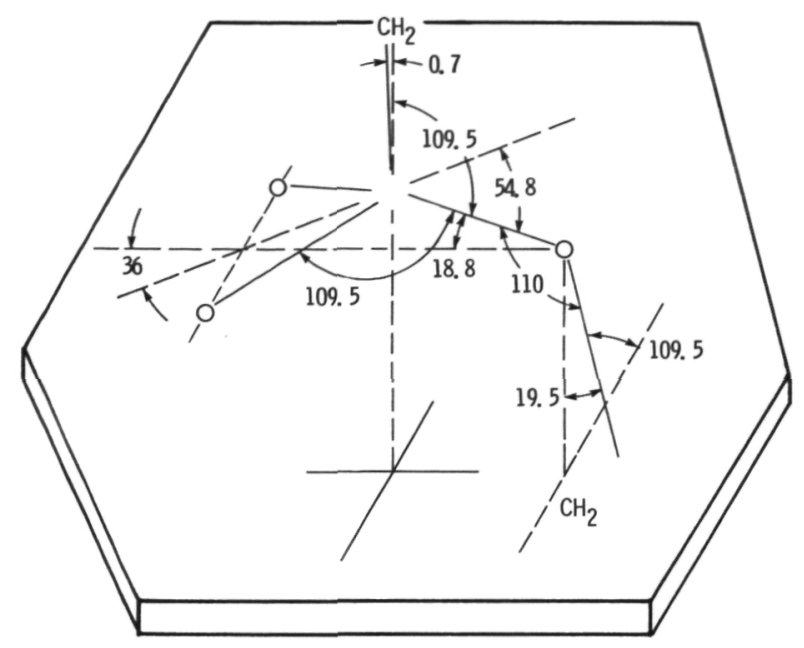

(b) Bonding of the surfactant (PMS) to a oxidized aluminum surface.

Fig. 9. - The use of quartir for the determination of molecular coordination of a surfactant (PMS) with a oxidized aluminum surface.

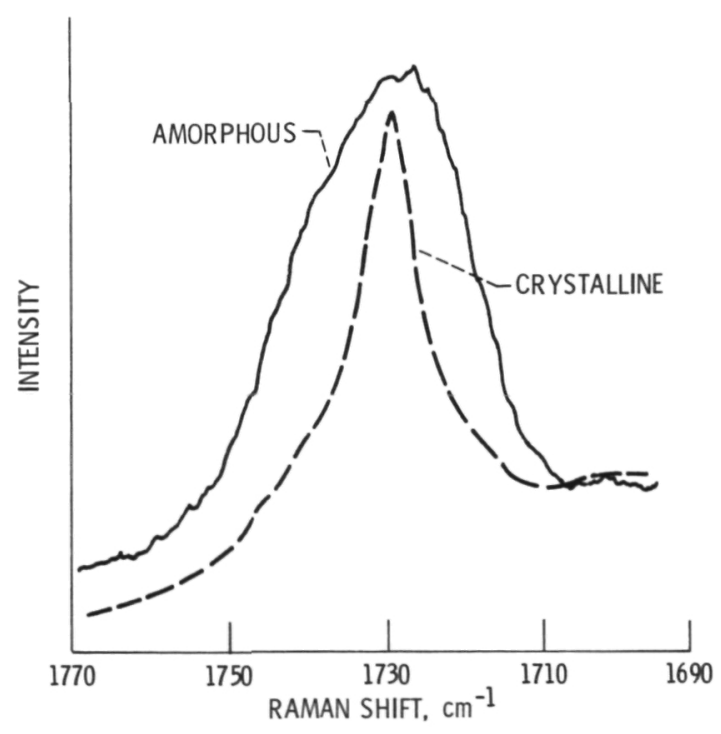

Fig. 10. - Raman spectrum of Mylar - appearance of the carbonyl stretching band of quenched and crystallized polyethylene terephthalate. 


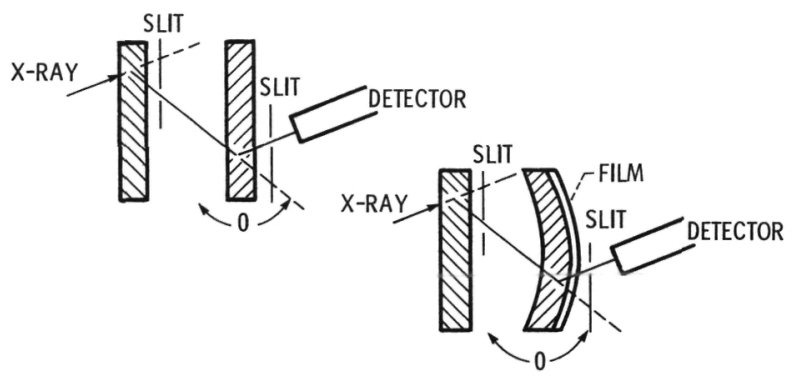

$\begin{array}{ll}\text { (a) With unstrained crystals. (b) With a strained crystal. } & \end{array}$

Fig. 11. - Schematic of double crystal camera arrangement

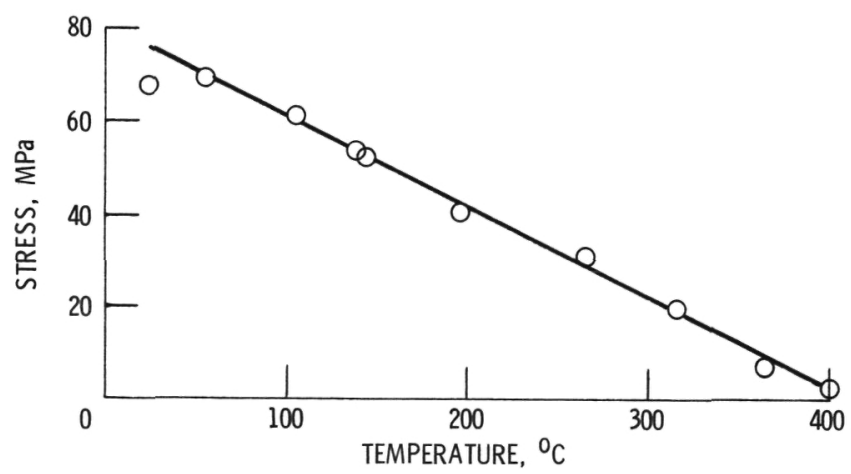

Fig. 12. - Plot of stress versus temperature for a polyimide film. 


\begin{tabular}{|c|c|c|c|c|}
\hline $\begin{array}{l}\text { 1. Report No. } \\
\text { NASA TM- } 83628\end{array}$ & \multicolumn{2}{|c|}{ 2. Government Accession No. } & \multicolumn{2}{|c|}{ 3. Recipient's Catalog No. } \\
\hline \multicolumn{3}{|l|}{ 4. Title and Subtitle } & \multicolumn{2}{|l|}{ 5. Report Date } \\
\hline \multicolumn{3}{|c|}{ Characterization and Measurement of Polymer Wear } & \multicolumn{2}{|c|}{$\begin{array}{l}\text { 6. Performing Organization Code } \\
506-53-1 \mathrm{~B}\end{array}$} \\
\hline \multicolumn{3}{|l|}{ 7. Author(s) } & \multicolumn{2}{|c|}{$\begin{array}{l}\text { 8. Performing Organization Report No. } \\
\text { E- } 2033\end{array}$} \\
\hline \multicolumn{3}{|c|}{ Donald H. Buckley and Paul R. Aron } & \multicolumn{2}{|l|}{\begin{tabular}{|l|}
10. Work Unit No. \\
\end{tabular}} \\
\hline \multirow{2}{*}{\multicolumn{3}{|c|}{$\begin{array}{l}\text { 9. Performing Organization Name and Address } \\
\text { National Aeronautics and Space Administration } \\
\text { Lewis Research Center } \\
\text { Cleveland, Ohio } 44135\end{array}$}} & \multicolumn{2}{|c|}{ 11. Contract or Grant No. } \\
\hline & & & \multirow{2}{*}{\multicolumn{2}{|c|}{$\begin{array}{l}\text { 13. Type of Report and Period Covered } \\
\text { Technical Memorandum }\end{array}$}} \\
\hline \multicolumn{3}{|c|}{\begin{tabular}{|l} 
12. Sponsoring Agency Name and Address \\
\end{tabular}} & & \\
\hline \multicolumn{3}{|c|}{$\begin{array}{l}\text { National Aeronautics and Space Administration } \\
\text { Washington, D.C. } 20546\end{array}$} & \multicolumn{2}{|c|}{ 14. Sponsoring Agency Code } \\
\hline \multicolumn{5}{|c|}{$\begin{array}{l}\text { 15. Supplementary Notes } \\
\text { Prepared for the International Symposium on Polymer Wear and Its Control } \\
\text { sponsored by the American Chemical Society, St. Louis, Missouri, April 9-11, } 1984 .\end{array}$} \\
\hline \multicolumn{5}{|c|}{$\begin{array}{l}\text { 16. Abstract } \\
\text { A host of analytical tools are available to assist the tribologist in understand- } \\
\text { ing and characterizing the polymer wear process. They can be used in the study } \\
\text { of polymer wear and the development of polymer transfer films to nonpolymer } \\
\text { counterfaces. Some of the devices discussed include visual observation of polymer } \\
\text { wear with SEM, quantifying it with surface profilometry and ellipsometry, studying } \\
\text { chemistry with AES, XPS and SIMS, establishing interfacial polymer orientation } \\
\text { and accordingly bonding with QUARTIR, polymer state with Raman spectroscopy and } \\
\text { stresses that develop in polymer films using a X-ray double crystal camera } \\
\text { technique. }\end{array}$} \\
\hline \multicolumn{5}{|c|}{ 18. Distribution Statement } \\
\hline \multicolumn{2}{|c|}{$\begin{array}{l}\text { Polymer; Friction; Wear; Adhesion; } \\
\text { Material transfer }\end{array}$} & \multicolumn{3}{|c|}{$\begin{array}{l}\text { 18. Distribution Statement } \\
\text { Unclassified - unlimited } \\
\text { STAR Category } 27\end{array}$} \\
\hline $\begin{array}{r}\text { 19. Security Classif. (of this report) } \\
\text { Unclassi fied }\end{array}$ & $\begin{array}{l}\text { 0. Security } \mathrm{Cla} \\
\mathrm{Ur}\end{array}$ & $\begin{array}{l}\text { spage) } \\
\text { fied }\end{array}$ & 21. No. of pages & 22. Price ${ }^{*}$ \\
\hline
\end{tabular}

"For sale by the National Technical Information Service. Sprıngfield, Virginia 22161 
National Aeronautics and Space Administration

Washington, D.C.

20546

Official Business

Penalty for Private Use, $\mathbf{\$ 3 0 0}$
SPECIAL FOURTH CLASS MAIL BOOK

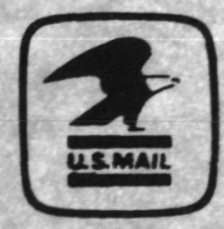

Postage and Fees Paid National Aeronautics and Space Administration NASA 451 